\title{
Factors Influencing Employee Retention in the Transport and Logistics Industry
}

\author{
Yvonne Sishuwa' ${ }^{1}$ Jackson Phiri² \\ ${ }^{1}$ Graduate School of Business, The University of Zambia, Lusaka, Zambia \\ ${ }^{2}$ Department of Computer Science, School of Natural Sciences, The University of Zambia, Lusaka, Zambia \\ Email: chibuyemachashi@gmail.com, Jackson.phiri@cs.unza.zm
}

How to cite this paper: Sishuwa, Y., \& Phiri, J. (2020). Factors Influencing Employee Retention in the Transport and Logistics Industry. Open Journal of Social Sciences, $8,145-160$.

https://doi.org/10.4236/jss.2020.86013

Received: November 26, 2019

Accepted: June 8, 2020

Published: June 11, 2020

Copyright $\odot 2020$ by author(s) and Scientific Research Publishing Inc. This work is licensed under the Creative Commons Attribution International License (CC BY 4.0).

http://creativecommons.org/licenses/by/4.0/

\begin{abstract}
Employee Retention is a process in which employees are encouraged to remain within an organization for the maximum period or until the completion of a project. Successful organizations need to do more than just hire the right people but retain the right people for the job. Failure to retain employees results in the loss of knowledge, experience, customer relations and technical skills which are taken to another organization. The aim of this study was to identify some of the major factors that affect employee retention in the transport and logistics industry servicing one of the largest mines in Africa, based in one of Zambia's rural areas, Solwezi. The objectives of this study were to identify the major factors influencing employee retention in the transport and logistics industry, to develop a framework based on a Causal Model and recommend possible solutions that could lead to improvements in employee retention. The study used a mixed methods approach comprised of the quantitative and qualitative methods. The computed sample from the population was 171 but only 144 respondents successfully participated in the study. Quantitative data was analysed using the statistical Package for Social Sciences (SPSS). Content analysis was also used to analyze data from the interviews with the key respondents. The findings established that retention was affected by job satisfaction, organizational commitment and workplace structures. However, individual characteristics did not have a significant influence on employee retention. From the findings, it was recommended that strategies aimed at improving the workplace structures, job satisfaction and organizational commitment be implemented to promote job security and career development, which were cited as some of the major factors influencing employee retention.
\end{abstract}

\section{Keywords}

Employee Retention, Job Satisfaction, Organizational Commitment, Individual Characteristics, Workplace Structures 


\section{Introduction}

This chapter is an introduction of a study focused on addressing some of the major factors influencing employee retention based on the Causal Model. Employees are the backbone of any organization; they are the most important resource in the attainment of organizational goals. There can be no success without human resource to utilize other resources to produce goods and services (Matindo et al., 2015). With the advent of globalization and competition in the global economy, organizations in Zambia need to anticipate technological innovations and compete at an international level.

It has been observed that employee retention is not determined by one factor but a cluster of issues (Fitz-enz, 1990). Focusing on a cluster of issues would have proved difficult given the time frame of this study, hence the adaptation of a Causal Model to provide a frame work of factors to be studied. The Causal Model proposes four models of job satisfaction and organizational commitment which are seen to influence the intent to stay. Its applicability to the transport and logistics industry will be studied to gain understanding of the factors that have an influence on employee retention.

The study was conducted in a rural area in Zambia which is home to one of the biggest mines named Kansanshi. The Mine produces an estimated 260,000 tonnes of copper a year, nearly $40 \%$ of Zambia's total output. This mine has a significant impact on the local businesses that pick up Mine related business worth over \$100 million dollars every year from Kansanshi. $65 \mathrm{~km}$ from this rural area called Solwezi, is Lumwana open-pit copper mine and a further $100 \mathrm{~km}$ away is Sentinel, a sister Mine of Kansanshi which is a $\$ 2.1$ billion project which also started production (The Solwezi Effect, 2016).

This has attracted several transport and logistics companies whose core business is providing transportation and logistical services to the mining industry within Solwezi and the surrounding areas.

Because of how lucrative the industry is, it is important to note that the industry is becoming very competitive. In addition, due to the similar nature of skills and experience required across all the companies in this industry, employee's can easily switch jobs from one company to another, carrying with them the business knowledge and strategies that give one business competitive advantage over the next. Therefore, it has become critical to the success of transport and logistics companies operating in Solwezi, to ensure that once successful attraction and recruitment of talent is done, active retention forms a key aspect of the company's overall talent management strategy. The motive behind this should be the understanding of how human resource is a critical source of competitive advantage especially in service oriented sectors such as transport and logistics. Despite huge investments in physical assets and technology, it is not possible to achieve effective and efficient execution of the supply chain ecosystem without the employees' contribution. The employees' actions empower the effective and efficient execution of the company's or the clients supply chain 
ecosystem (Millar, 2015).

The Solwezi transport and logistics industry offers services to Zambia's economic engine, statistics from the work done by the International Council on Metals and Mining (ICMM), verified data from 2012 statistics that, in that year $86 \%$ of the foreign direct investment that came into Zambia was due to the mining industry, $80 \%$ of the country's export earnings came from the mining industry as well as over $25 \%$ of all revenues collected (Sikamo et al., 2016). The paragraph above highlights the importance of the transport and logistics industry in Solwezi because of the role it plays in the mining industry supply chain. Mining products rely heavily on the transportation sector in Solwezi for the movement of its products and raw materials, from and to the mining sites.

A key component of this sector is the human resource tasked with the coordination of the entire process to ensure it is done efficiently and effectively. Therefore, it should interest not only the transport and logistics industry of Solwezi but the macro economy because understanding the best strategies to retain talented employees has a ripple effect on the productivity of the mining industry when there are inefficiencies in the transport and logistics industry.

Research Objectives

1) To identify the major factors influencing employee retention in the transport and logistics industry;

2) To develop a framework based on the Causal Model for assessing employee retention in the transport and logistics industry;

3) Based on the model in (2), recommend possible solutions that will improve employee retention in the transport and logistics industry.

Research Questions

1) What are some of the major factors influencing employee retention in the transport and logistics industry?

2) How can we develop a model based on the Casual Model in order to address the factors identified in (1) for the transport and logistics industry?

3) How can the major factors factor that affect the transport and logistics industry in (1) be addressed based on the model in (2)?

\section{Literature Review}

1) Employee retention

Employee retention is a process in which employees are encouraged to remain in an organization for the maximum period (James \& Mathew, 2012). According to Kaila (2012) retention is important as it prevents the following:

Turnover, interruption of customer service and loss of a company's goodwill. Turnover leads to turnover and impacts on efficiency and company knowledge maybe lost to competitors once an employee leaves to join a competitor (Figure 1).

In assessing the causes of employee turnover which is the opposite of retention, the Causal Model assumed the dominant view that job satisfaction was the 
cause of greater organizational commitment. Workplace structures and individual characteristics were presumed to influence job satisfaction and organizational commitment, which in turn affected employees' intent to stay in the organization, the presence of which, translates into employee retention. Currivan (as cited by James and Mathew, 2012), proposed in his research, four Models a) satisfaction precedes commitment b) Commitment precedes satisfaction c) satisfaction and commitment have a reciprocal relationship and d) satisfaction and commitment have no significant relationship. However, the results could not determine this causality significantly hence the continuing view that both job satisfaction and commitment work together since the more positive emotions an employee feels such as job satisfaction, the more likely they are to be committed to an organization and ultimately stay in an organization or rather, be retained by it. Having no conclusive findings, the Causal Model was used to develop a conceptual framework using job satisfaction, organizational commitment, individual characteristics and workplace structures.

2) Job Satisfaction

Job satisfaction is an affectionate response by people towards their jobs and is basically the degree that people like their jobs. People that like their jobs are less likely to quit. Job satisfaction has an inverse effect on turnover among workers and it is one of the variables in the Causal Model that will be used as a basis for this study, in an attempt to understand what leads to employee retention.

3) Organizational Commitment

Organizational commitment will measure the employees' attachment to their organizations, it has been suggested that employees who exhibit high organizational commitment are less likely to leave the organization voluntarily (Chelliah et al., 2015). Employees bonded with their work are less likely to leave. As working environment, relationships with superiors, workload, social support, compensation and company rules and regulations among others (James \& Mathew, 2012).

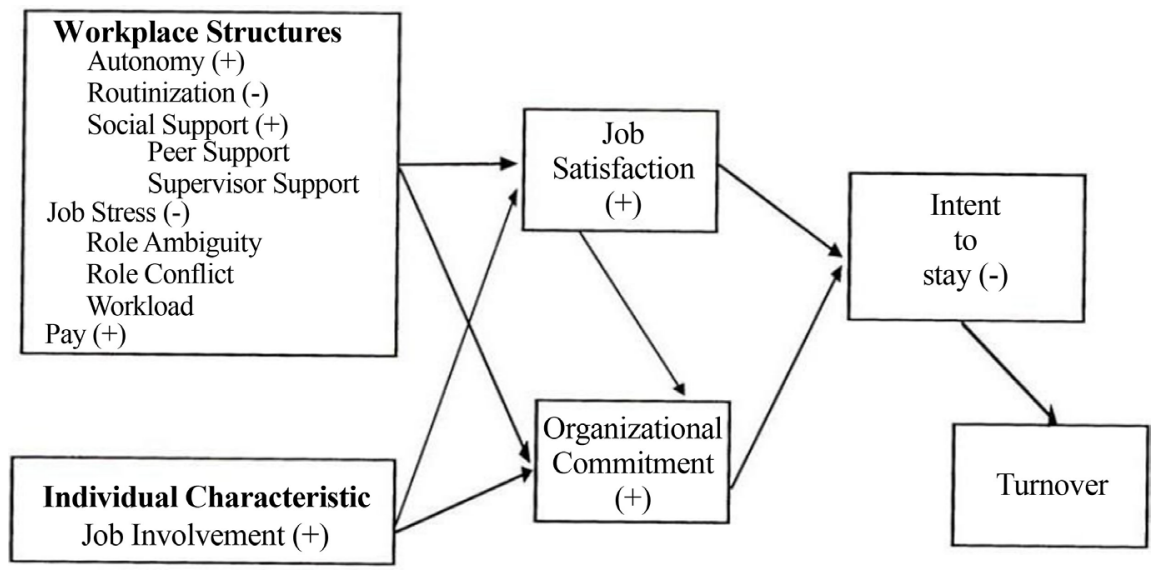

Figure 1. The Causal Order of Job Satisfaction and Organizational Commitment. Source: Currivan (1999). 


\section{4) Workplace Structures}

Workplace structures refers to the way the different parts of an organization collaborate with one another to achieve organizational objectives.

5) Individual Characteristics

The demographic profile of the employees will be measured also and its impact on retention, for example, literature reviews have revealed that both length of service and age of employees plays are associated with voluntary leaving, it is difficult to retain employees who are younger and those who have been on the job for a short period of time compared to those who are older and have served for longer periods (ibid).

6) Intent to stay

The intention to stay is a tendency by employees to retain their membership with the current organizations (Currivan, 1999). Intent to stay is an indicator of near and distant turnover action and it negatively affects turnover (Ghiselli et al., 2001). As earlier stated, employee retention is an act by the employer to retain an employee while intent to stay is a behavior by the employee, the two can be viewed as two sides of the same coin.

8) Related Works

In a study by Samuel and Chipunza (2009) on employee retention and turnover using motivational variables as a panacea in 4 South African Companies from the private and public sectors, identified intrinsic and extrinsic motivational variables were studied to determine the extent to which they influenced employee retention and led to a reduction in turnover.

Skilled employees in South Africa are migrating to other countries for better job conditions. A survey revealed that South African employees were among the top performing employees in the United States of America, Italy, German, Brazil and Britain. This explains why South African employees are constantly poached by Multinational companies (Gillingham, 2008). It is against such a background that employers need to develop and apply the right retention strategies or continue losing valuable employees. The researchers formulated the fundamental question as follows; "To what extent are intrinsic and extrinsic motivational variables being used in influencing retention and reduction of turnover of employees in both public and private sector organizations". The variables identified as the most influential were training and development, job security, challenging or interesting work and freedom for innovative thinking.

According to Hay (as cited by Samuel and Chipunza, 2009), training and development was determined as one of the most critical elements of any retention strategy used by managers to retain the best employees. Other researchers such as Bussin (2002) argued against the benefits of training and employee development because providing employees with the latest training and development opportunities raises their market value thus increasing their ability to join other employers. The strong evidence of association between job security and retention was attributed to the socio-economic stability and psychological wellbeing of individuals in stable employment. Challenging and interesting work moti- 
vated employees based on the different aspects of their work which resulted in opportunities to have the freedom for innovative thinking.

It was thus concluded that employers had a growing need to retain employees in the face of competition both locally and globally. To do so, the variables stated above are crucial in influencing employees' decision to either leave or remain in an organization (Samuel \& Chipunza, 2009).

In 2015 a study was done at Kitwe Central Hospital to investigate the factors affecting the retention of employees. The retention of employees has been a challenge in the Zambian health sector in the dynamic era of Globalization and competition. In the study, the country was found to be facing a significant shortage in skilled health workers which also affects the few available health workers in the country because they are overworked and have consequently, become demotivated (Matindo et al., 2015).

The Zambian government in partnership with the Netherlands in 2003 (Makasa, 2008) devised the Zambia Health Workers Retention Scheme (ZHWRS) which is an incentive strategy aimed at the attraction, retention and increasing availability of workers in the rural areas. Other efforts in the health sector have been made to retain employees leaving the country, such as agreements between SADC countries not to hire health professionals from other member states and the WHO intervention in Africa to help governments to boost salaries and improve recruitment and training. In the findings, out of the $97 \%$ of respondents, at least $53 \%$ of the employees were happy with their jobs describing their roles as challenging. It was discovered that $79 \%$ of the employees would have loved to work elsewhere. The findings revealed that poor working conditions, poor salaries and incentives, lack of career growth, poor management styles, in-conducive work environments, job insecurity, global and national economy, lack of motivation, lack of equipment and drugs and work overload recorded higher percentage rate (Matindo et al., 2015).

Though this study was done in the Zambian context, it was limited to Kitwe Central Hospital and, the findings and recommendations cannot be generalized to all the other organizations in the country unless a study is done to establish the applicability of the factors identified in the $\mathrm{KCH}$ retention study in relation to the Causal Model which accounts for an employee's intention to stay in an organization.

\section{Methodology}

1) Conceptual Framework

A conceptual framework is a structure which the researcher believes can explain the natural phenomenon to be studied (Camp, 2001). It describes from the researcher's perspective, how the research problem will be explored. The relationship of the main concepts of this study was thus described with the aid of a conceptual framework (Adom et al., 2018).

Based on the Causal Model a framework of 3 independent variables; job satis- 
faction, organizational commitment and workplace structures was developed. Also, the dependent variable determined was employee retention, measured by the intent to stay. To analyze the influence of the independent variables in Figure 2, the following hypotheses will be used to test the relationship:

a) $\mathrm{Ho}=$ job satisfaction has influence on employee retention

$\mathrm{H} 1$ = job satisfaction has no influence on employee retention

b) $\mathrm{Ho}=$ organizational commitment has influence on employee retention

$\mathrm{H} 1$ = organizational commitment has no influence on employee retention

c) $\mathrm{Ho}=$ workplace structures has influence on employee retention

$\mathrm{H} 1=$ workplace structures has no influence on employee retention

2) Sample Size

The sample size of the study was determined using the Yamane formula (Israel, 2003) where; $n=$ sample size, $N=$ the size of the population $15 e=$ the error of 5 percentage points. The respondents were randomly selected from a sample size with an error of $5 \%$ and with confidence coefficient of $95 \%$. From an estimated population of 300 , the sample size was determined using the Yamane Formula as follows;

$$
n=N /\left(1+N e^{2}\right) ; \text { where } N=300, e=5 \%
$$

when the formula was applied, the following sample was derived:

$$
300 / 1+300(0.0025)=171 .
$$

The sample size of 171 was broken down into 168 questionnaires for ordinary employees while the remaining 3 questionnaires were for key respondents representing the employers in the transport and logistics industry.

3) Data Collection Procedures

168 semi structured questionnaires were distributed but only 144 could be retrieved given the available time and willingness of the participants. 3 key respondents in management were purposefully sampled and interviewed. A total of 144 respondents in total participated successfully in the study and this upon establishing contact with the respondents who agreed to participate in the study, the nature of the study was explained.

Independent Variable

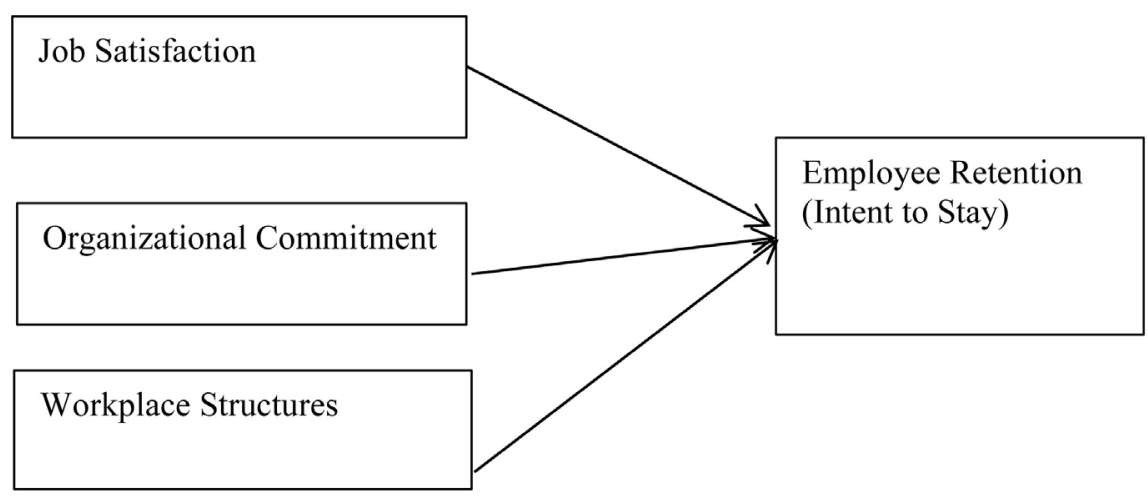

Figure 2. Conceptual framework based on the causal model source: author, 2019. 
4) Sources of Data

Both primary and secondary sources of information were used in this study of retention based on the Causal Model of employee retention. A semi-structured questionnaire was developed consisting of 5 main variables, namely individual characteristics, workplace structures, job satisfaction, organizational commitment and intent to stay. Individual characteristics questions sought to establish the demographic profile of the respondents while the other variables employed questions on a Likert scale with responses such as strongly agree, neutral, disagree and strongly disagree. The other set of questions were on the satisfaction to dissatisfaction scale providing for responses in one of the following categories; highly dissatisfied, dissatisfied, neutral, satisfied and highly satisfied. The question of what recommendations the respondents had, was open ended.

Semi-structured interviews were also another source of data, a set of pre-determined questions was used but additional probing and open questions were asked throughout the interviews. This approach prevented the interview from becoming too rigid and enabled the researcher to thoroughly explore the participants' responses. For example, the key respondents were asked if they had any policies aimed at employee retention and were they stated yes, a follow up question was asked to gain further understanding of what these policies were and what sort of retention factors they were aimed at addressing.

The rationale for using semi-structured interviews and semi-structured questionnaires in the study was firstly, to have an opportunity to gather data on what was being done by the employer to retain employees and the challenges they were facing and secondly, to gather data from the employees' perspective, so the gaps between the two, if any could be bridged resulting in appropriate recommendations. The secondary data was sourced mainly from online sources such as databases or internet findings. Journal articles of relevant studies were used and sourced from goggle scholar.

5) Sampling Methods

Purposive sampling was used in this study, companies in the town of Solwezi operating in the transport and logistics industry were selected. 4 companies fit this criterion in Solwezi, 4 of which were approached and only 3 were willing to participate in the study hence the use of Convenience Sampling. All the existing departments in all 3 organizations were included in the sample selection but the respondents who received the questionnaire were those available during the researchers visit to the companies because majority of employees in these organizations are shift workers. Random Sampling of employees from all the departments in each company was done to ensure the participants represented all sections in each of the 3 companies.

One key informant from each of the 3 companies was interviewed using an interview guide and they were be purposively selected.

6) Data Analysis

Quantitative data from the semi-structured questionnaires was analyzed using Statistical package for Social Sciences (SPSS) to create frequency tables, simple 
descriptions, cross tabulations and Mann Whitney tests for hypothesis testing. Excel was used to create tables and graphs from the information generated in SPSS. Correlation analysis was done to determine which factors influenced retention.

To analyze the interview and open-ended question responses, the questionnaires and handwritten notes were read repeatedly, and key ideas or statements highlighted. Once the themes were determined, content analysis was used to classify the information into categories responding to the research questions on what the major factors of employee retention were, and recommendations made for improving these factors.

\section{Results and Discussions}

The data collected was analyzed using the data analysis tools described in the methodology and the results presented using figures and tables.

1) Individual Characteristics

Figure 3 shows the gender distribution of the respondents, $84 \%$ are males and $16 \%$ are females, it can be concluded that the transport and logistics industry in the study is a male dominated industry. Figure 4 shows the age group distribution; $27.7 \%$ of the age group were between 30 - 34 years, $22 \%$ were in the age group between 25 - 29 years, $18.4 \%$ were between 35 - 39 years, $10.6 \%$ were between 40 - 44 years, $8.5 \%$ were between $20 \%$ - 24\%, $6.4 \%$ were between $45-49$ years, $4.3 \%$ were between 50 - 54 years and $1.4 \%$ were between 60 - 64 years of age.

Figure 4 and Figure 5 illustrate the findings of the level of education and length of service of the respondents. Majority of the respondents attended tertiary education (college/university) represented by $73 \%$ of the sample, $23.4 \%$ had been to secondary school, 3.5 had some other form of education while $7.1 \%$ did not respond to the question. In terms of length of service, the majority of respondents had served between 1 and 5 years in the transport and logistics industry.

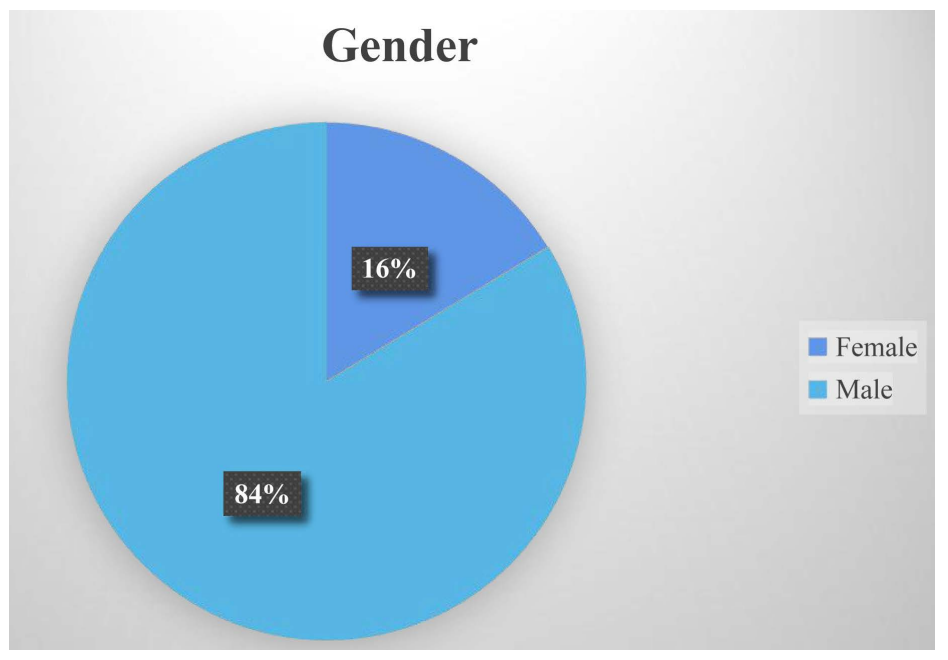

Figure 3. Sample distribution by gender. Source: Author, 2019. 


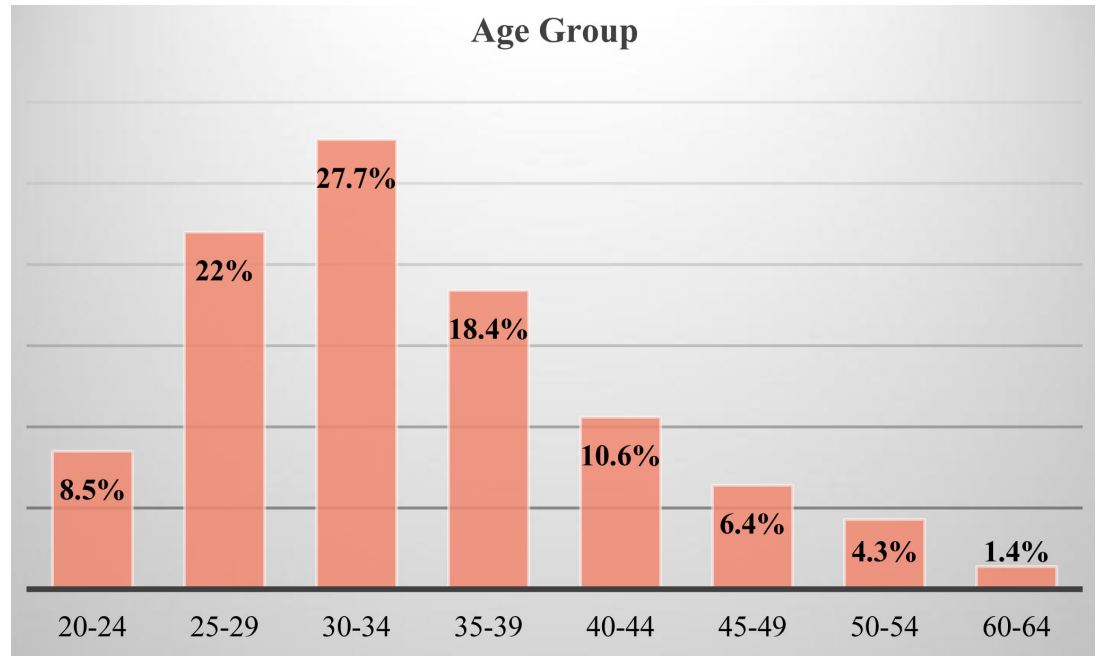

Figure 4. Percentage distribution by Age group. Source: Author, 2019.

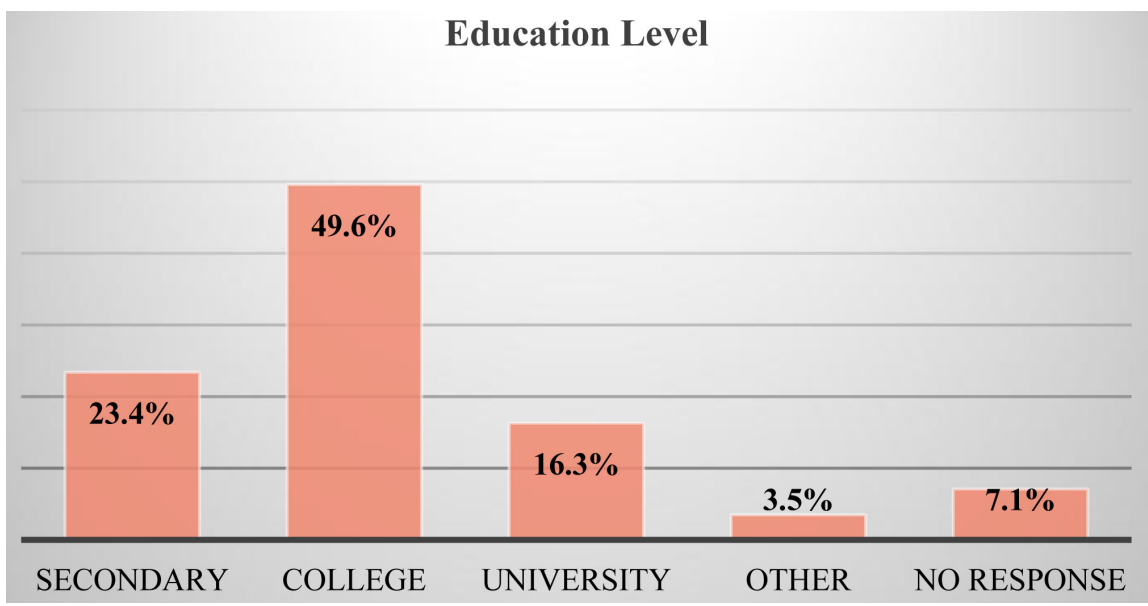

(a)

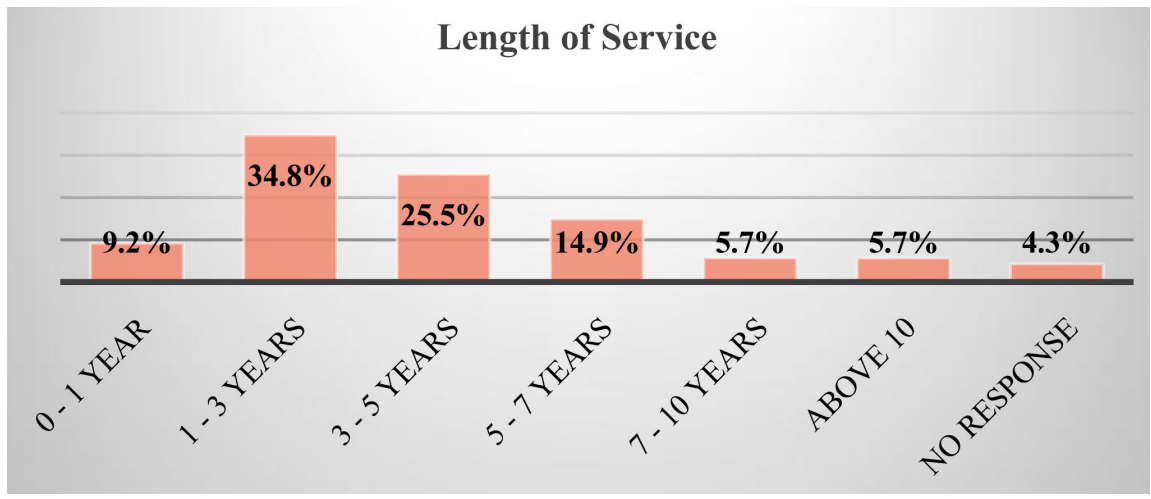

(b)

Figure 5. (a) Percentage distribution by Education Level; (b) Percentage distribution by length of service. Source: Author, 2019.

2) Intent to Stay

Figure 6 illustrates the findings in response to respondents' intent to stay in the organization, $80 \%$ intended to stay in the organization while $16 \%$ indicated 
no when asked if they intended to stay in the organization and $4 \%$ did not respond to the question.

Figure 7 illustrates the response from the respondents when asked if they were actively searching for another job, 55.32\% indicated No, 34.75\% indicated Yes and a final 9.93\% did not respond.

3) Job Satisfaction and Organizational Commitment

Table 1 shows the results obtained from the cross tabulation of organizational commitment and retention (intent to stay). The majority of those who agreed and strongly agreed to feeling committed to their organization also scored highly on intent to stay with the organization.

4) Non-Parametric Tests

To determine whether or not there is a relationship among the independent and dependent variables, non-parametric tests were conducted in testing the hypotheses. The Mann-Whitney $U$ test was conducted on ordinal data which included workplace structures, job satisfaction and organizational commitment Table 2 is a cross tabulation of job satisfaction and employee retention(intent to stay), the majority of the respondents who agreed and strongly agreed to job satisfaction also stated yes to their intent to stay with their employers.

Table 3: Conclusion; according to the Mann Whitney $U$ test, the P-value (0.032) is less than the significant level 0.05 , hence the test is significant and we fail to reject the null hypothesis. Therefore, it can be concluded that there is evidence to suggest that workplace structures have influence on employee retention.

Table 4: Conclusion; according to the Mann Whitney test, the P-value $(0.00772)$ is less than the significant level 0.05 , hence the test is significant and we fail to reject the null hypothesis. Therefore, it can be concluded that there is evidence to suggest that job satisfaction has influence on employee retention.

Table 5: Conclusion; according to the Mann Whitney test, the P-value (0.0098)

\section{Intent to Stay}

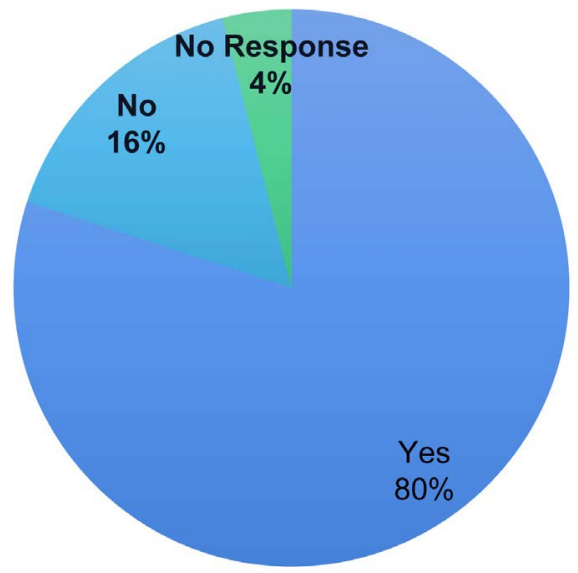

Figure 6. Intent to stay in organization. Source: Author, 2019. 


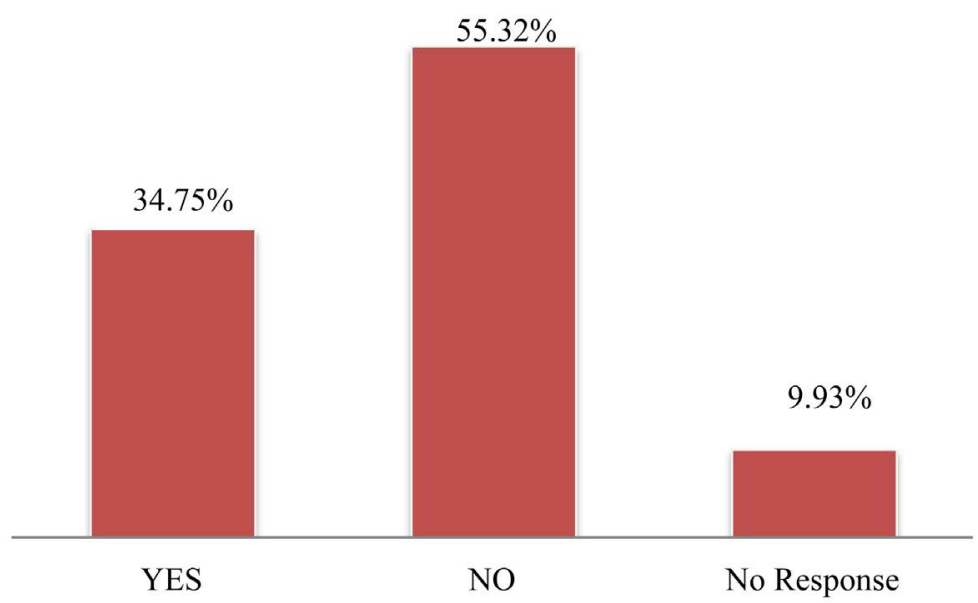

Figure 7. Respondents actively searching for another job. Source: Author, 2019.

Table 1. Cross tabulation of organizational commitment and employee retention (Intent to stay).

\begin{tabular}{ccc}
\hline Organizational Commitment and Employee Retention (Intent to Stay) & \\
\hline & Yes & No \\
\hline Strongly Disagree & 1 & 2 \\
Disagree & 3 & 4 \\
Neutral & 21 & 7 \\
Agree & 41 & 9 \\
Strongly Disagree & 45 & 1 \\
Total & 111 & 23 \\
\hline
\end{tabular}

Source: Author, 2019.

Table 2. Cross tabulation of job satisfaction and employee retention (Intent to stay).

\begin{tabular}{ccc}
\hline \multicolumn{3}{c}{ Job Satisfaction and Employee Retention } \\
\hline & Yes & No \\
\hline Highly Dissatisfied & 2 & 2 \\
Dissatisfied & 9 & 3 \\
Neutral & 35 & 13 \\
Agree & 42 & 5 \\
Strongly Disagree & 23 & 5 \\
Total & 111 & 28 \\
\hline
\end{tabular}

Source: Author, 2019.

Table 3. Work place structures vs employee retention.

\begin{tabular}{cc}
\hline \multicolumn{2}{c}{ Mann-Whitney Test Statistics } \\
\hline Working Place Structures vs Employee Retention \\
\hline Mann-Whitney U & 1004.0000 \\
Wilcoxon W & 1304.0000 \\
Z & -2.139 \\
Asymp. Sig. (2 tailed) & 0.032
\end{tabular}

Source: Author, 2019. 
Table 4. Job satisfaction vs employee retention.

\begin{tabular}{cc}
\hline \multicolumn{2}{c}{ Mann-Whitney Test Statistics } \\
\hline Working Place Structures vs Employee Retention \\
\hline Mann-Whitney U & 1315.00 \\
Wilcoxon W & 1615.00 \\
Z & -0.313 \\
Asymp. Sig. (2 tailed) & 0.00772 \\
\hline
\end{tabular}

Source: Author, 2019.

Table 5. Organizational commitment vs employee retention.

\begin{tabular}{cc}
\hline \multicolumn{2}{c}{ Mann-Whitney Test Statistics } \\
\hline \multicolumn{1}{c}{ Working Place Structures vs Employee Retention } \\
\hline Mann-Whitney U & 1353.500 \\
Wilcoxon W & 7794.5 \\
Z & -0.015 \\
Asymp. Sig. (2 tailed) & 0.0098 \\
\hline
\end{tabular}

Source: Author, 2019.

is less than the significant level 0.05 , hence the test is significant and we fail to reject the null hypothesis. Therefore, it can be concluded that there is evidence to suggest that organizational commitment has influence on employee retention.

\section{Recommendations}

While majority of the employee respondents intend to stay with the organizations that have currently employed them, at least $34.7 \%$ in Figure 7 were actively searching for a job. This is quite significant, and employers must make improvements focused on the areas identified as having influence on employee retention such as workplace structures, organizational commitment and job satisfaction, if they intend to significantly reduce the percentage of respondents who are searching for another job. It must be noted that while the majority intend to stay, due to the changing needs of a human being, intent to stay at one stage is not a guarantee of intent to stay at a later stage hence the need for employers to take a proactive approach when tackling matters of employee retention.

The respondents made recommendations that called for the implementation of strategies which fell under at least one or more of the following themes, job security, improved rules and regulations, career development opportunities, competitive compensation and benefits and improved conditions of service. The themes that occurred most often are job security implemented through longer contract terms. The results suggest that organizations in the transport and logistics industry that want to improve employee retention and gain competitive advantage, need to employ strategies with a focus on work place structures in the 
many dimensions that it takes. This recommendation is similar to Walker (2001) who identified 7 factors that enhance employee retention, and these are; compensation and appreciation for work performed, provision of challenging work, chances to be promoted or to learn, invitational atmosphere within the organization, positive relations with colleagues, a healthy balance between professional and personal life and good communications.

In addition to improved workplace structures, organizational commitment also needs to be improved in order to enjoy high levels of employee retention. According to Curtis and Wright (2001) an important indicator of employee retention is organizational commitment, employees who strongly identify with their organization, value the sense of membership within it and agree with its objectives and value systems are not only likely to remain with an organization but also work considerably hard on its behalf.

Regarding job satisfaction, it was observed in Table 2, that a significant number of respondents were neutral about job satisfaction which leads the researcher to draw the conclusion that strategies aimed at increasing job satisfaction levels which influences employee retention need to be improved. The level of job satisfaction is influenced by both intrinsic and extrinsic motivation factors. The extrinsic factors include job security, physical working conditions, pay and benefits; while intrinsic factors include recognition, promotion, freedom, learning opportunities, nature of the job and status (Armstrong, 2010). Strategies could take the form of annual salary reviews based on merit and organizational performance, regular labor market salary surveys to review if the organizations' compensation is competitive in the industry, regular staff surveys assessing work place structures, job satisfaction and organizational commitment would help organizations gain an understanding of areas requiring improvements from the employees' perspective.

\section{Conclusion}

Based on the findings of this study, it can be concluded that the frame work applicable to the transport and logistics industry when addressing is one considering workplace structures, job satisfaction and organizational commitment as factors having an influence on employee retention in the transport and logistics industry.

\section{Limitations}

The study focused on the transport and logistics industry in Zambia given both time and financial constraints, however this study could be carried out in a wider transport and logistics industry while paying attention to enable the generalization of the research findings to the rest of the transport and logistics industry.

\section{Acknowledgements}

My gratitude goes to everyone who supported me throughout this research. 
Thankful to all the respondents who took the time to participate in this study and the entire Management of the Graduate School of Business at the University of Zambia.

\section{Conflicts of Interest}

The authors declare no conflicts of interest regarding the publication of this paper.

\section{References}

Adom, D., Joe, A.-A., \& Hussein, E. K. (2018). Theoretical and Conceptual Framework: Mandatory Ingredients of Quality Research. International Journal of Scientific Research, 7, 438-441.

Armstrong, M. (2010). Essential Human Resource Management Practice, a Guide to People Management. New Delhi: Kogan Page Ltd.

Bussin, M. (2002). Retention Strategies: Remuneration Answers. Johannesburg: Knowledge Resources.

Camp, W. G. (2001). Formulating and Evaluating Theoretical Frameworks for Career and Technical Education Research. Journal of Vocational Educational Research, 26, 27-39. https://doi.org/10.5328/JVER26.1.4

Chelliah, S., Sundarapandiyam, N., \& Vinoth, B. (2015). A Research on Employee Organisational Commitment in Organisations. A Case of SME'S in Malaysia. International Journal of Managerial Studies and Research (IJMSR), 3, 10-18.

Currivan, D. B. (1999). The Causal Order of Job Satisfaction and Organizational Commitment in Models of Employee Turnover. Human Resource Management Review, 9, 495-524. https://doi.org/10.1016/S1053-4822(99)00031-5

Curtis, S., \& Wright, D. (2001). Retaining Employees-The Fast Track to Commitment. Management Research News, 24, 59-64. https://doi.org/10.1108/01409170110782964

Fitz-enz, J. (1990). Getting and Keeping Good Employees. In Personnel, 67, 25-29.

Ghiselli, R. F., Lopa, J. M., \& Bai, B. (2001). Job Satisfaction, Life Satisfaction, and Turnover Intent among Foodservice Managers. The Cornell Hotel and Restaurant Administration Quaterly, 42, 28-37. https://doi.org/10.1177/0010880401422002

Gillingham, A. (2008). Skills and Clientele Vanish. Sunday Times, 28 September, 17.

Israel, G. D. (2003). Determining Sample Size. University of Florida. https://www.tarleton.edu/academicassessment/documents/Samplesize.pdf

James, L., \& Mathew, L. (2012). Employee Retention Strategies: IT Industry. Journal of Indian Management, 9, 79-89.

Kaila, H. L. (2012). Human Resource Development and Business Growth. New Delhi: I.K International Publishing House Ltd.

Makasa, E. (2008). The Human Resource Crisis in the Zambian Health Sector: A Discussion Paper. Medical Journal of Zambia, 35, No. 3.

https://doi.org/10.4314/mjz.v35i3.46522

Matindo, J., Karodia, A. M., \& Pekeur, S. (2015). An Investigation of the Factors Affecting Retention at Kitwe Central Hospital. Journal of Business Management Review (Nigerian Chapter), 3, 81-106. https://doi.org/10.12816/0011651

Millar, M. (2015). Battle for Talent in the Logistics Sector: Retention Strategies (pp. 10-11). LSC World (IN) Mark Millar 0315. 
Samuel, M. O., \& Chipunza, C. (2009). Employee Retention and Turnover Using Motivational Variables as a Panacea. African Journal of Business Management, 3, 410-415.

Sikamo, J., Mwanza, A., \& Mweemba, C. (2016). Copper Mining in Zambia-History and Future. Journal of Southern Africa Institute of Mining and Metallurgy, 116, 491-496. https://doi.org/10.17159/2411-9717/2016/v116n6a1

The Solwezi Effect (2016) https://miningforzambia.com/the-solwezi-effect/

Walker, J. W. (2001). Zero Defections? Human Resource Planning, 24, 6-8. 